\title{
Non-invasive integrated study of groundwater resources in Southern and South-Eastern Asia: geochemical prospectives
}

\author{
MAJID KHAN $^{1}$ AND MUHAMMAD HASAN ${ }^{2}$
}

${ }^{1}$ International School for Optoelectronic Engineering, Qilu University of Technology (Shandong Academy of Sciences), 250353, Jinan, China Email: majid.khan@mail.iggcas.ac.cn

${ }^{2}$ Institute of Geology and Geophysics, Chinese Academy of Sciences, 100029, Beijing, China Email:

hasanmjiinnww@gmail.com

Despite being rich in groundwater resources, assessment of saline-water intrusion in South and South-East Asia is a big challenge given the complex environmental system. However, analysis of groundwater quality is essential for the estimation of freshwater resources in this region where nearly half of the world's population is living. Traditionally, geochemical study is performed by collecting and testing of groundwater samples from boreholes using a number of laboratory tests. However, such techniques are expensive and time consuming, and still cannot analyze groundwater quality over a large area. To select the non-invasive key methods towards this end, an integrated approach of geophysical and geochemical study is introduced. Our results show that, in case of sparse water samples, our proposed approach can assess the groundwater quality within diverse environment of any area with $90 \%$ confidence. 